\title{
Mimetismos Afro-Brasileiros: dependências e algumas formas de ser
}

\author{
Leonardo Oliveira de Almeida ${ }^{1}$ \\ ${ }^{1}$ Universidade Federal do Ceará, Fortaleza, CE, Brasil
}

\section{Resumo}

O argumento central deste artigo é o de que, no Rio Grande do Sul, as transformações no campo afrorreligioso estão acompanhadas por processos de modulação do axé. Esses processos podem ser observados a partir do universo material e possibilitam que certos objetos atuem de diferentes formas, por meio de múltiplos avatares. Isso só é possível devido às dinâmicas de diferenciação, atualização e individuação das forças que atuam no mundo (axé/energias), próprias do universo religioso afro-brasileiro, situadas em um "constante jogo dialético entre o mesmo e o outro" (AUGRAS, 2008, p. 21). Como consequência, tal como buscarei argumentar, surgem processos miméticos - mimetismos afro-brasileiros - que se mostram como desafios de pesquisa e que podem ser observados em controvérsias que eclodem no campo afrorreligioso. Para abordar tais questões, aponto para a circulação e o movimento dos tambores no campo afro-gaúcho. Por fim, considero que este artigo contribui para um debate mais amplo acerca das materialidades religiosas afro-brasileiras.

Palavras-chave: Tambores. Modulação do Axé. Mimetismos Afro-Brasileiros.

\section{Afro-Brazilian Mimicry: dependencies and modes of being}

\begin{abstract}
The main argument of this article is that the transformations in the Afro-religious field in Rio Grande do Sul (Brazil) are involved by processes of axé modulation. These processes can be observed from religious materialities and allow certain objects to act in different ways, from multiple avatars. This is only possible due to the dynamics of differentiation and individuation of the forces (axé/energias), situated in a "constant dialectical game between o mesmo and o outro" (AUGRAS, 2008, p. 21). As consequence of these dynamics, certain mimetic processes - Afro-Brazilian mimicry - appear to the ethnographer and can be observed in controversies that arise in the Afro-religious field. To approach these issues, I follow the movement and the circulation of the drums in the Afro-Gaucho field. Finally, I believe this article contributes to a broader debate about Afro-Brazilian religious materialities.
\end{abstract}

Keywords: Drums. Axé Modulation. Afro-Brazilian Mimicry. 


\section{Introdução}

[...] é preciso desdobrar-se para transformar-se. Tornar-se outro, diferente em tudo e, no entanto, idêntico. (SANTOS, 2012, p. 270)

E m um de seus textos, Brent Plate $(2015$, p. 3$)$ nos traz a seguinte afirmação: "The objects extend human agency, but humans also extend the agency of the objects, and the objects have some agency with or without humans". Essa afirmação, um tanto comum entre os estudos sobre materialidades ou no contexto do que se convencionou chamar de material turn ("virada material") nos estudos antropológicos, diz muito sobre os modos de ser e, por vezes, é compreendida de forma a supor certa tangibilidade dos agentes ou, como chamou Bruno Latour (2012), um caráter "ostensivo" dos seres do mundo. Essa maneira de compreender as coisas e os objetos, caso seja transposta para o campo das religiões afro-brasileiras, faz emergir alguns problemas. Nas religiões afrogaúchas, universo em que este artigo está embasado, e, de modo geral, nas religiões afro-brasileiras, realizar distinções entre o agente I e o agente II com frequência revela ser uma tarefa desafiadora. Esse desafio pode ser observado, por exemplo, na complexa relação entre pessoas, energias, divindades e objetos que participam de feituras religiosas.

Uma boa maneira de exemplificar essa "inostensividade" dos seres pode ser iniciada a partir da noção de axé, já bastante discutida nos estudos sobre as religiões afro-brasileiras. Barbosa Neto (2017) nos lembra que essas religiões constituem um rico e diversificado conjunto de modos de existência, no interior do qual é possível distinguir a presença de certas regularidades que, em complemento, não apresenta qualquer uniformidade. Dessa forma, destaca o autor, trabalhos mais recentes parecem dedicados a encontrar a melhor maneira de descrever essa variação, ou seja, a inventar um modo de apreender as conexões e separações entre as diferentes formas assumidas por essas religiões no Brasil. No campo das constâncias, a noção de axé ganha certo protagonismo, uma vez que pode ser encontrada em etnografias realizadas nas diferentes regiões do país.

Nessa trilha, Roger Bastide e Marcio Goldman nos trazem duas expressões que contribuem para os argumentos que serão apresentados neste artigo. Goldman (2009) destaca que, nas religiões afro-brasileiras, há um constante trabalho de modulação do axé. Essa expressão faz referência ao fato de que, em todos os espaços dos terreiros e, de modo especial, nos processos de feitura, as forças que atuam no mundo estão sendo confirmadas, particularizadas, intensificadas ou tendo sua intensidade reduzida, renovadas, atualizadas, plantadas, transferidas. Há, para Barbosa Neto (2012, p. 265), 
um aspecto propriamente artesanal e artístico nas religiões afro-brasileiras e que consiste em saber usar todas essas forças para fazer e desfazer formas.

Roger Bastide (1983), por sua vez, ressalta que os rituais de iniciação, feitura e consagração possibilitam que pessoas, objetos, lugares, oferendas e altares participem das mesmas "forças místicas". Assim, por exemplo, após a realização de certos procedimentos rituais, um colar de contas de um iniciado, bem como seu corpo e o assentamento do seu orixá, torna-se participante de uma mesma força particularizada. Há diferentes maneiras de aproximar-se das forças e das intensidades do mundo, pois, como diria o próprio Bastide (1961, p. 339), “[...] há coisas que participam mais e que participam menos [...]" e que, em complemento, existe "[...] toda uma série de graus de participação". Goldman (2009, p. 123) acrescenta à discussão ao afirmar que "[...] a unidade dessa força garante que tudo participa em tudo, mas as suas modulações fazem com que haja graus de participação [...]", ou, ainda, de acordo com Juana Elbein dos Santos (2012, p. 41), pois "[...] a qualidade do asè varia segundo a combinação dos elementos que ele contém e vincula".

As religiões afro-gaúchas, que aqui serão compreendidas a partir dos diferentes tipos de tambor que atuam nesse universo religioso, nos mostram que as dinâmicas de movimento e de circulação de pessoas, forças e objetos não estão desligadas das participações e modulações que os envolvem. Dessa forma, o argumento central que será discutido ao longo deste artigo é de que, no Rio Grande do Sul, as transformações no campo afrorreligioso estão acompanhadas por processos de modulação do axé, o que possibilita que diferentes versões de um mesmo objeto ${ }^{1}$, no caso, os tambores, possam atuar de diferentes formas. Assim, quando, por exemplo, por motivos de incompatibilidade energética, um objeto é impossibilitado de ocupar certos espaços ou de atuar de determinadas maneiras, uma espécie de avatar, agora apto a atuar, é convidada a participar do circuito de ação. Isso só é possível devido às dinâmicas de diferenciação, individuação e de atualização das forças que atuam no mundo, situadas no que Augras (2008, p. 21) considera ser um "[...] constante jogo dialético entre o mesmo e o outro". Tais ajustamentos se mostram pertinentes para a compreensão do campo afro-gaúcho, em especial se considerarmos o encontro entre Umbanda, Quimbanda e Batuque, modalidades afrorreligiosas que se estabeleceram em períodos distintos nessa região do país e que estão envoltas em dinâmicas de deslocamentos e passagens (de pessoas, práticas, materiais, etc.), bem como de compatibilidades e incompatibilidades entre energias, divindades e práticas rituais.

Uma das consequências dessas dinâmicas, tal como buscarei argumentar, é o surgimento de certos processos miméticos que se mostram como desafios de pesquisa e que podem ser observados em controvérsias que eclodem no interior do campo afrorreligioso. Ora, os avatares podem nos confundir. Trarei para o centro deste artigo três versões desses instrumentos que se distinguem por particularidades que serão descritas adiante: o tambor de obrigação, o tambor de trabalho e o tambor da casa. Para abordar os mimetismos protagonizados por esses instrumentos, dei especial atenção ao movimento de tambores e alabês (pessoa que toca tambor nos terreiros) no campo religioso afro-gaúcho. Estes últimos, os alabês, são, na companhia de seus ilús (tambores), responsáveis pela condução

Ao colocar a expressão mesmo objeto em destaque, busca-se ressaltar certo incômodo em supor uma unidade desses instrumentos. 
ritual e musical nos terreiros, atividade marcada pelas práticas do andejo (BARBOSA NETO, 2017) e da circulação entre diferentes templos e modalidades religiosas (Umbanda, Quimbanda e Batuque). Acompanhar esses objetos e pessoas em trânsito possibilitou analisar alguns aspectos relacionados ao que chamarei de mimetismo afro-brasileiro. Comecemos pela discussão dessa noção² .

\section{Mimetismos Afro-Brasileiros}

O locutor de um documentário sobre camuflagem animal pedia aos espectadores que observassem um ramo de orquídeas brancas. Na imagem, pétalas de formatos diversos balançavam horizontalmente ao receber o sopro das correntes de ar. Após alguns segundos, um leve movimento passa a se destacar. Algo se mexe em outros ritmos, mas ainda não é possível identificar o que está se movendo. Pouco depois, um novo movimento, agora mais intenso, denuncia e dá mais nitidez às formas. Sem que o locutor indicasse o que causava o estranhamento e, obviamente, já supondo que ali deveria haver um animal, pude identificar um louva-a-deus branco (Hymenopus coronatus - Louva-a-deus orquídea) em meio às pétalas, quase invisível ao primeiro olhar, um pouco mais visível ao moverse levemente e mais bem compreensível quando da intensificação dos movimentos. Era possível ver as patas dianteiras curvadas, os olhos grandes, as protuberâncias brancas nas costas, entre outros detalhes. Aquele me pareceu um importante enunciado sobre a importância dos movimentos e suas diferentes intensidades à percepção. Poderíamos citar, ainda, como estímulos à reflexão, as dinâmicas de sobreposição e fundo, as tentativas de identificação de contrastes, o ofuscamento constante de formas e contornos. A exemplo do reino animal, camuflagens e mimetismos nos fazem pensar sobre certos processos de invisibilização.

Bruno Latour (2012) destacou uma relação possível entre estabilidade e invisibilidade, momento em que certas coisas são esquecidas ou não vistas porque as associações de que participam nos parecem já estabilizadas. É precisamente isso que dá forma ao que chamo de mimetismo ${ }^{3}$. Este se expressa quando, por exemplo, os aspectos estéticos ou sonoros de certos tipos de tambores, os tambores de trabalho, tornam invisíveis outros tipos de tambores, os tambores de obrigação, estando o segundo mimetizado sobre o fundo produzido pela performance do primeiro. Ele, o tambor de obrigação, está lá, mas sua presença pode não ser percebida. Proponho uma caminhada reflexiva que visa a dar atenção especial ao movimento e à circulação, apostando nestes como importantes geradores de visibilidade, pois, de forma particular, permitiram que versões distintas de um "mesmo objeto" fossem exploradas do ponto de vista analítico e etnográfico. Como afirma Latour (2012, p. 230), “[...] se fazem outras coisas mover-se e você consegue

\footnotetext{
Este artigo é resultado de um processo de pesquisa realizado entre 2015 e 2018 e que teve como objetivo compreender a atuação dos tambores utilizados nas religiões afro-brasileiras do Rio Grande do Sul, em um contexto de transformações no campo religioso e de intenso uso de "novas mídias" e tecnologias. A pesquisa foi realizada nas cidades de Porto Alegre, Alvorada, Gravataí, Viamão, Esteio, Eldorado do Sul e Guaíba - ver Almeida (2019).

3 Para além das distinções entre camuflagem e mimetismo, uma vez que ambos os processos poderiam ser utilizados como metáforas para os casos analisados neste artigo, utilizarei mimetismo como um termo genérico que indica certos processos de invisibilização. Tampouco há aqui a necessidade de estabelecer, do ponto de vista antropológico, a distinção entre mimesis e mimicry a partir da ideia de intencionalidade, tal como fez Hoehne (2009).
} 
registrar esses movimentos, então são visíveis". Aqui, diferentes tipos de movimento nos mostram relações e possibilitam a identificação de certos contrastes.

De partida, busco discutir de que forma os diferentes processos de consagração (ou de não consagração) põem os tambores em movimento no campo religioso afro-gaúcho. Esses movimentos acontecem a partir da mediação de distintos avatares, daí resulta que os instrumentos anunciem formas distintas de alcance e atuação. Tal processo de avatarização aponta para uma característica marcante nas religiões afro-gaúchas: cada alabê possui seu próprio tambor ${ }^{4}$, sendo este levado para diferentes terreiros, situações e modalidades rituais. Ao circularem, ao colocarem em prática seu papel de "geômetras da religião" (BARBOSA NETO, 2017), os alabês nos mostram deslocamentos, situações distintas que pedem tambores distintos. Mas é importante considerar, e talvez esse seja um dos principais problemas das análises até então produzidas sobre o tema, que os tambores também impõem diferentes intensidades de movimento aos alabês.

Discutirei mimetismo a partir de dois focos. Primeiro, considero que há um mimetismo que se apresenta ao pesquisador como um desafio de identificar versões de tambores e torná-las visíveis. É importante considerar que, na prática religiosa, os agentes estabelecem formas de distinção entre esses instrumentos. Em um segundo sentido, o mimetismo se expressa nas dinâmicas protagonizadas pelos próprios interlocutores. Nessa segunda dimensão, controvérsias surgem quando certos mimetismos são revelados, porque em algum momento certos tambores não são vistos ou são confundidos com outros. Essa questão será discutida na última parte deste texto, a partir de um debate protagonizada por dois alabês durante um programa de entrevistas transmitido ao vivo nas redes sociais.

\section{Ilú e Inhã}

Alguns autores (KREBS, 1988; GIDAL, 2016; CORRÊA, 2006; 2011; 2014; BRAGA, 1998 ) consideram a existência de dois tipos de tambor nas religiões afro-brasileiras do Rio Grande do Sul: o ilú, ou simplesmente "tambor", e a inhã $\tilde{a}^{5}$ Krebs (1988, p. 75), por exemplo, é enfático ao anunciar a existência das duas versões do instrumento:

Só há dois tipos no Rio Grande do Sul tradicional: o inhã, tronco de cone alongado, feito com aduelas de madeira e tendo doze búzios ao redor da pele maior, vedado a mãos femininas, e o tambor cilíndrico, geralmente feito com latas de óleo vazias. Sempre pintados com cores religiosamente simbólicas. Correspondem aos atabaques baianos.

Corrêa (2006, p. 112) comenta que a inhã é, em relação ao ilú, “[...] bem maior [e] tem forma de tronco de cone, [...]. Enquanto mulheres podem tocar no primeiro [o ilú], só homens tocam neste último [a inhã]". Braga (1998, p. 98) acrescenta que “[...] apesar de chamar-se inhã (substantivo feminino), ela é considerada um tambor

\footnotetext{
Em outras partes do país, considerando-se as especificidades regionais das religiões afro-brasileiras e de matriz africana, é comum que os tambores usados nos rituais sejam dos terreiros, e não dos alabês.

5 É importante considerar a existência (menos numerosa) de alguns terreiros que utilizam atabaques, tumbadoras ou congas, tal como apresentado por Gidal (2016) e Silveira (2008).
} 
masculino ${ }^{6}$ e pertence exclusivamente a xangô $[\ldots]^{\prime \prime}$, por isso, é comumente pintado de branco e vermelho.

Figura 1 - Inã - Pai Didi de Xangô

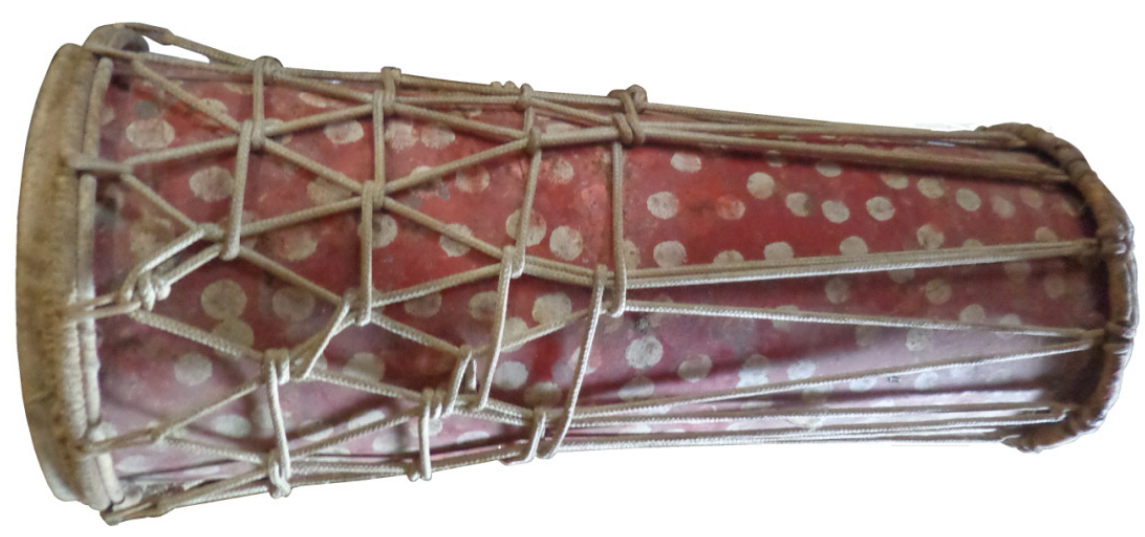

Fonte: Elaborada pelo autor deste artigo (2016)

A inhã é utilizada apenas em rituais de Batuque, não sendo percutida em rituais de Umbanda e Quimbanda, além de ser considerada um tambor pronto e, por isso, apenas tamboreiros prontos podem tocá-la. Ser "pronto", nesse caso, significa que o tamboreiro realizou rituais de obrigação com sacrifícios de animais quadrúpedes para os 12 orixás cultuados no Batuque. Levando em conta esse aspecto, Braga (1998, p. 99) discorre sobre o "desaparecimento" desse tambor nos terreiros gaúchos:

É um tambor 'pronto' e por isso, somente os tamboreiros 'prontos' podem tocá-lo. Talvez, seja uma das razóes para o seu desaparecimento na maioria das casas mais recentes, onde ainda não há um quadro de tamboreiros que tenham passado pelo aprontamento na religião, um processo que pode levar anos até se concretizar.

O impulso de profissionalização vivenciado pelos alabês nos últimos 20 anos vem estimulando o surgimento de cursos pagos e a entrada de diversos religiosos no mercado dos tocadores de tambor, resultando em desencontros entre o tempo necessário ao toque da inhã e o tempo necessário ao toque do ilú. Este último não requer o aprontamento religioso, o que o torna, não por acaso, o instrumento mais popular entre os alabês. Soma-se a isso o crescimento da Quimbanda (ORO, 2002; LEISTNER, 2014; GIUMBELLI; ALMEIDA, $2021)$ que, entre outras influências, vem tornando cada vez mais atrativas as estéticas preferidas dos exus, como o uso de tambores com sonoridades mais agudas ${ }^{7}$ e os ritmos animados do toque jêje, melhor executados no ilú. Uma vez que a inhã é utilizada apenas em rituais de Batuque, seu uso não acompanha a intensa popularização da Quimbanda no Rio Grande do Sul. Assim, sugiro que o "desaparecimento" da inhã possui forte relação com a profissionalização e com os acelerados processos de aprendizagem, bem como com a valorização das estéticas, performances e sonoridades ligadas à Quimbanda e seu grande crescimento nos últimos anos.

\footnotetext{
Norton Corrêa (2014, p. 170) descreve a inhã: “O outro, em tronco de cone, é chamado de inhã - a inhã - do gênero feminino".

7 Comparando o ilú e a inhã, Norton Corrêa (2011, p. 63) afirma que: “Enquanto os outros [os ilús] são afinados em tom agudo, a inhã, também por suas dimensões e forma, é mais grave [...] o 'contrabaixo da orquestra'".
} 
Durante o processo de pesquisa, e em comparação ao ilú, pouco ouvi a respeito da inhã. Seu nome me foi apresentado quase sempre quando os religiosos faziam referência a um passado que não presenciaram ou a alabês mais antigos. Pude encontrá-la poucas vezes, apenas quando pedi a alguns pais de santo para que me mostrassem as inhãs de suas casas ou quando da primeira vez que participei de um arissum, o ritual para os mortos. Da parte dos alabês, conheci apenas dois que a possuíam, sendo estes também pais de santo. Por esse motivo, centrarei minhas reflexões apenas nos ilús, uma vez que esse é o instrumento mais utilizado pelos alabês gaúchos e também o que melhor contribui com os argumentos que serão apresentados neste artigo.

O ilú, também chamado apenas de tambor, “[...] tem a forma cilíndrica (e não cônica, como a Inhã) e é um bimembranofone unipercursivo, ou seja, possui duas peles tampando as duas extremidades e é executado percutindo-se somente uma das peles" (BRAGA, 1998, p. 98). É comumente percutido na posição vertical, entre as pernas, estando a parte inferior do instrumento apoiada nos tornozelos do alabê, evitando que o couro toque o chão. Um complexo sistema de nós pressiona os couros sobre as duas extremidades do instrumento. É o instrumento amplamente utilizado nos terreiros gaúchos.

Figura 2 - Ilú - alabê Etto Mendes

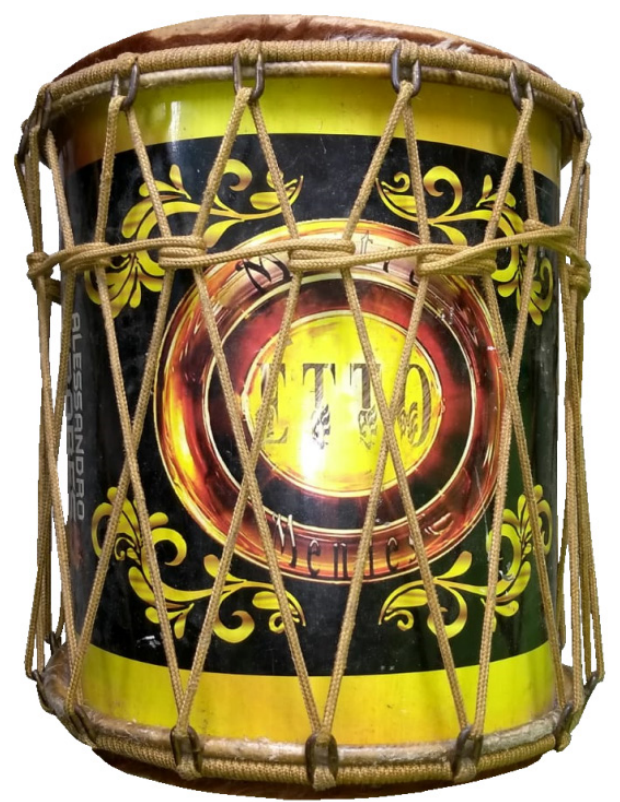

Fonte: Elaborada pelo autor deste artigo (2016)

Coerente com os argumentos que venho expondo até agora, gostaria de trazer para discussão algumas expressões desse instrumento. Se, por um lado, os aspectos estéticos do ilú e da inhã, bem como seus respectivos nomes, usos e sonoridades orientaram a distinções entres esses dois instrumentos, resultando muitas vezes em uma classificação dualista dos tambores gaúchos, a possibilidade de acompanhar alabês e tambores em diferentes espaços ao longo do processo de pesquisa me levou a considerar outros tipos de distinção. Estes estão embasados nos diferentes processos de consagração e circulação a que são submetidos os ilús, possibilitando a existência de distintos avatares desse instrumento. Iniciarei pela apresentação dos tambores de obrigação e dos tambores 
de trabalho. Por vezes, um único tambor desempenha os dois papéis (de obrigação e de trabalho), principalmente nos períodos iniciais da carreira dos alabês, mas a tendência é que esses papéis venham a ser separados em instrumentos distintos num dado momento da trajetória religiosa e profissional. Por fim, apresentarei um terceiro instrumento, o tambor da casa. Esses três tambores, lembremos, são ilús.

Seguir esses instrumentos em processos de circulação, ou seja, nos deslocamentos entre terreiros, estúdios de gravação, casas de alabês, rituais em espaços públicos e lojas de artigos religiosos, me mostrou a atuação de outras versões além daquelas já anunciadas por Krebs, Bastide, Herskovits, Braga, Gidal, Corrêa, entre outros. Por enquanto, opto por suspender a distinção quase dual "ilú e inhã", pois, como veremos, falta-lhe movimento. O processo de profissionalização dos alabês gaúchos é também acompanhado por uma intensa circulação desses tambores entre as diferentes modalidades religiosas (Batuque, Umbanda e Quimbanda), o que resulta na existência de certos ajustamentos quanto à atuação desses instrumentos.

Nesse sentido, é importante destacar que o Batuque, a Umbanda e a Quimbanda são as três modalidades afrorreligiosas presentes de forma mais intensa no Rio Grande do Sul. O Batuque (que se divide em nações ou "lados", como oyó, jeje, ijexá, cabinda e nagô) dedica-se ao culto dos orixás e está presente no território gaúcho desde o século XIX. A Umbanda, por sua vez, dedica-se ao culto dos caboclos, pretos velhos e crianças e chegou ao Rio Grande do Sul na década de 1930. A Quimbanda caracteriza-se pelo culto aos exus e "suas mulheres míticas" (CORRÊA, 1988), as pombagiras, e é comumente apresentada como um culto que adquiriu sua independência ritual a partir da década de 1970, quando se constituiu como um dos ramos gerados a partir da prática umbandista. A maioria dos terreiros gaúchos afirma praticar as três modalidades (ORO, 2002; CORRÊA, 2006), em momentos distintos do calendário ritual e, em alguns casos, em espaços distintos dentro de uma mesma "casa de religião". A existência desses três corpos rituais e suas interações implica na presença de dinâmicas de forças e energias presentes no mundo, o que, como veremos, relaciona-se com os diferentes tambores que atuam no campo afrorreligioso.

\section{Tambor de obrigação e tambor de trabalho}

Qualquer consideração sobre a presença dos objetos nas religiões afro-brasileiras requer uma análise atenta aos processos de consagração religiosa, pois, de alguma forma, os atravessam. Isso quer dizer que batizar, preparar, aprontar, fazer são verbos que comumente circundam ou fazem parte dos próprios modos de existência dos objetos nessas religiões. No caso dos tambores, Melville Herskovits (1944) e Gerard Béhague (1984), entre outros autores, destacaram desde tempos que o batismo confere a esses instrumentos novas maneiras de agir. Herskovits (1944), por exemplo, também mencionou o perigo de tambores não batizados atuarem de maneiras indesejadas. Os casos que serão apresentados neste artigo, por outro lado, evidenciam que a ausência de consagração, que em alguns contextos pode ser compreendida como um fato problemático ou indesejado, também pode existir em uma perspectiva positiva. Em suma, consagração e ausência de consagração não são necessariamente pares opostos, mas podem ser modos complementares de existência 
que se tornam possíveis na medida em que certos tambores estão situados em relações de dependência. Explorarei melhor essas questões.

Entre os alabês com quem tive oportunidade de conversar e de conviver ao longo do período de pesquisa, os processos de consagração dos tambores apresentam variações quanto às divindades para as quais os instrumentos são consagrados, situações e procedimentos a serem realizados. Também apresentam especificidades quanto aos sacrifícios animais, duração e procedimentos a serem seguidas. Por outro lado, há certa recorrência quanto à existência de dois tipos de tambor (ambos ilú) que permeiam as experiências religiosas desses alabês e que podem nos auxiliar na compreensão dos diferentes tipos de movimento e de consagração a que são submetidos esses instrumentos: os tambores de obrigação, instrumento consagrado que desempenham papel importante na obrigação religiosa do iniciado e que possui pouca ou quase nenhuma circulação, se comparados aos tambores de trabalho; e o tambor de trabalho, comumente submetido a outros tipos de consagração (ou ausência de consagração), apropriando o instrumento para a atividade profissional e, consequentemente, para a circulação e para a atuação em diferentes situações e modalidades rituais. É importante destacar que a pouca circulação dos tambores de obrigação é relativa, se limitando muito mais ao aspecto material do que ao campo das forças. Isso aponta para certos processos de fragmentação, pois, como será exposto, parte do tambor circula enquanto a outra parte permanece reclusa.

É possível acompanhar esses alabês por meses sem que tal distinção seja citada ou percebida durante a prática ritual e profissional. Como pretendo argumentar, os tambores de obrigação nos aparecem, à primeira vista, mimetizados na forma de tambor de trabalho. Apesar de atuar intensamente durante a atividade dos alabês, o tambor de obrigação pode passar despercebido ao observador atraído pela visualidade e sonoridade que os tambores de trabalho provocam. Mesmo não aparecendo aos sentidos mais imediatos, está presente na forma de axé e manifesta-se como autorização, proteção, conhecimento, memória, potência rítmica e força. Expliquemos melhor.

Em entrevista, o alabê Douglas Coimbra, que é artesão e produz tambores por encomenda no bairro Rubem Berta, em Porto Alegre, me contou que possui três tambores. Entre eles, "um, que é o da obrigação, fica no terreiro, não sai, e só eu toco" utiliza esse instrumento apenas em rituais de Batuque realizados em seu terreiro. Para os toques "pra fora", em outros terreiros, utiliza seus outros dois tambores. O alabê Frank Morais, morador da cidade de Alvorada, me contou sobre a atuação diferenciada de seus tambores, enquanto conversávamos diante dos instrumentos espalhados pelo chão. Referindo-se a um deles, Frank disse: "Esse (o tambor de obrigação) é o tamborzinho do meu axé . Esse tambor eu não quero mais sair pra rua com ele. Tamborzinho bom, eu adoro ele, toquei muita coisa com ele esse tempo que eu toco tambor. Eu vou guardar ele só pra tocar Batuque aqui em casa"10. Outro alabê, Bryam de Avagã, possui três tambores: "um da minha obrigação, que não sai de casa. Tá no meu quarto de santo. Só toco quando

\footnotetext{
8 Entrevista realizada em julho de 2016.

9 Refere-se ao axé de tambor, expressão que será discutida mais adiante.

10 Entrevista realizada em setembro de 2016.
} 
é serão [rituais de sacrifício] do meu pai [orixá], só quando eu tô indo pro chão. E os outros dois, que é o que eu uso pra trabalhar"11.

Há, portanto, uma distinção entre tambores de obrigação e tambores de trabalho, sendo estes últimos os instrumentos "da rua", submetidos a maiores regimes de circulação não apenas entre terreiros, mas também em outros espaços de atuação dos alabês, como estúdios de gravação, cursos de tambor, programas de $\mathrm{TV}^{12}$. Tal distinção não deve ser desperdiçada do ponto de vista analítico, pois, como veremos, indica algumas particularidades e transformações do campo religioso afro-gaúcho.

É importante ressaltar que em nenhuma situação foi a mim permitido tocar, ver ou fotografar qualquer um dos tambores de obrigação guardados nos quartos de santo dos meus amigos alabês. Esses instrumentos, que "não saem de casas", são guardados sobre estantes situadas nos quartos de santo, onde são também postos os assentamentos dos orixás dos filhos do terreiro, e permanecem cobertos por cortinas. Nesses casos, embaso-me exclusivamente nas descrições dos meus interlocutores. Por outro lado, alguns alabês costumavam manter seus tambores de obrigação fora do quarto de santo, ainda que restritos ao espaço da casa. Nesses casos, pude vê-los.

Uma boa forma de iniciar a discussão sobre os processos de consagração desses instrumentos seria retomando uma noção que Goldman (2012, p. 271) chama de "[...] um vocabulário um pouco antigo". Refiro-me à já citada ideia de participação utilizada por Roger Bastide em diversos de seus trabalhos. Tomando emprestado o termo de LevyBruhn, sem deixar de imprimir-lhe críticas, Roger Bastide (1961) considera os sistemas de participação do homem às divindades. Fala-se que o iniciado põe a cabeça em participação, pois participa do caráter das divindades, ou, ainda, faz participar de maneira cada vez mais profunda da natureza e da força das divindades.

Essa noção não deve ser compreendida sem considerarmos que, nas religiões afro-brasileiras, a descrição das divindades

[...] procede por via descendente, começando com a enumeração do que os fiéis por vezes denominam "orixás gerais", passando para suas qualidades [no caso do Batuque gaúcho, Xangô Agodô e Xangô Agandjú, por exemplo] e terminando, por vezes, com a menção de um certo número de orixás individuais. (GOLDMAN, 2005, p. 2)

Disso resulta que o processo de consagração ou aprontamento religioso implica uma particularização. Um orixá não é apenas o orixá, mas o meu orixá, no sentido de que, ao passo em que a pessoa é feita, os orixás também são feitos de forma única no decorrer de sua historicidade.

Nesse processo, pessoas e orixás fazem-se também em participação aos objetos. É por esse motivo que Roger Sansi $(2009 ; 2011)$ ressalta a importância da historicidade na análise dos altares nas religiões afro-brasileiras, argumentando que estes são mais do que representações ou símbolos do sagrado. Esses objetos não são símbolos abstratos, mas índices concretos da memória de uma relação pessoal entre "santo" e devoto. Nesse sentido, a consagração dos tambores, sobretudo os tambores de obrigação, embasa-se em

\footnotetext{
11 Entrevista realizada em agosto de 2016.

12 Em Almeida $(2018 ; 2019)$ abordei a atuação dos alabês gaúchos junto a programas de TV, gravação de CDs e DVDs, transmissões ao vivo pelo Facebook e a relação com empresas de marketing e mídia voltadas para o público afrorreligioso.
} 
um processo que "[...] particulariza os deuses para cada indivíduo. Logo após a aquisição do objeto [...] dá início ao processo de inserção deste no sistema dos objetos religiosos, reformando-os e sacralizando-os de modo particular para cada iniciado" (AMARAL, 2001, p. 3). Após a realização de certos procedimentos rituais, os elementos incluídos na feitura ou obrigação religiosa tornam-se participantes de uma mesma força particularizada.

Como poderíamos compreender, portanto, a expressão "não sair de casa" a que os alabês se referem? Além disso, como compreender a relação entre as limitações à circulação e os processos de consagração e particularização? André de Aganjú, alabê e pai de santo que possui terreiro no bairro Partenon, em Porto Alegre, nos auxilia: "Existe uma feitura, um axé de tambor que é feito pro tamboreiro. Este tambor ele é recluso ao quarto de santo, ele fica como se fosse um axé, como se fosse um santo na prateleira, fica esse tambor guardado".

Outro alabê, Luis de Xapanã, possui um tambor de obrigação de madeira, diferente de seus outros três tambores que são, "vamo dizer assim, tambores de trabalho"13, feitos de PVC ou chapa de metal.

Tu faz a obrigação junto com ele [tambor de obrigação], quando a gente deita com o orixá, a gente coloca o tambor junto. Ele faz uma obrigação contigo, ele vai pro chão contigo. Ele é uma coisa intocável, ele é uma coisa sagrada. Sem ele, sem o meu tambor, hoje eu não seria praticamente nada. Ele que é a base principal, ele é o esteio pra dar o seguimento pra aquilo que eu faço. Ele que conduz minha energia, na questão rítmica.

Luis, assim como André, afirma que o tambor de obrigação compõe um assentamento como os outros. De acordo com os ensinamentos que recebeu de seu pai de santo, pai Antônio Carlos de Xangô, o tambor deve ser consagrado ao orixá de cabeça do alabê, no caso de Luis, à Xapanã. Para todos os alabês citados até aqui, a consagração do tambor de obrigação é realizada apenas uma vez, durante a obrigação do alabê para seu orixá de cabeça, tal como nos casos de Luis e André, ou, em boa parte dos casos, para Xangô (o orixá dono do tambor $)^{14}$. Em ambos os casos, o instrumento se une a outros objetos para compor o orixá assentado e se torna uma espécie de representante dos demais tambores que serão eventualmente construídos ou adquiridos, além de conferir ao alabê o passe para o universo dos legítimos tocadores de tambor.

Durante a consagração do seu instrumento, que aconteceu durante o serão (sacrifício) ${ }^{15}$, Luis recebeu do tamboreiro Antônio Carlos o axé de tambor, também citado por André. $\mathrm{O}$ axé de tambor faz referência a uma qualidade de axé que deve ser transmitida de um

\footnotetext{
${ }^{13}$ Entrevista realizada em junho de 2018.

14 Por esse motivo, as consagrações dos instrumentos são comumente realizadas a partir do sacrifício de animais ligados a esse orixá. Ao final do processo, é posto no quarto de santo um assentamento de Xangô (incluindo o tambor), mesmo que este não seja o orixá de cabeça do iniciado. A associação de Xangô com os tambores pode ser encontrada em diversos estudos sobre as religiões afro-brasileiras. Corrêa $(2014$, p. 171), por exemplo, afirma que “[...] a orquestra [...], como um todo, pertence a Xangô, considerado o 'dono do barulho' (isto é, da música)". Luis Nicolau Parés (2014, p. 155), sobre o tambor abatá do Tambor de Mina, afirma: "O termo abatá lembra o iourubá bàtá, o tambor especial de Xangô". Wolff (2016, p. 79) afirma que “[...] o tambor é um objeto que é vinculado ao orixá Xangô, por este motivo ele deve primeiramente receber o sangue dos animais de preferência do orixá para animá-lo".

${ }^{15} \mathrm{O}$ axorô (sangue) do animal sacrificado deve escorrer sobre o corpo do tambor de obrigação, sobre as mãos do alabê e sobre os demais objetos que irão compor o assentamento do orixá a ser guardado no quarto de santo.
} 
alabê que já a possui ao alabê que irá recebê-la na obrigação ${ }^{16}$. Ao final do processo, o ocutá (a pedra do orixá/o próprio orixá) e as demais partes que compõem o assentamento (guardados no quarto de santo), o alabê e o tambor estarão participando, para utilizar novamente a expressão de Bastide, de uma mesma "força mística".

Durante uma de nossas conversas, Luis lançou uma questão:

Xapanã (seu orixá de cabeça) responde ${ }^{17}$ no tambor [de obrigação] e no ocutá? Eu acredito que o meu orixá não responda no meu tambor. Apenas no meu tambor tá a energia do meu orixá, a energia que foi canalizada pra ele. Meu orixá responde no ocutá, na minha cabeça, no ori. Mas o tambor, em si, ele se torna sagrado porque foi sacralizado pra aquilo ali, foi energizado naquela situação. Por isso que ele também se torna um assentamento.

O tambor assentado compõe o orixá em um acontecimento que pode ser mais bem compreendido a partir de uma perspectiva de relação que de propriedade (RABELO, 2015). Como lembra Miriam Rabelo (2015, p. 244), trata-se de “[...] um campo inteiro de dependências, em que cada ser depende de muitos outros para existir, ou ainda, em que cada ser contribui potencialmente para a feitura de muitos outros". Não é no tambor que o orixá responde, mas no ocutá que, por sua vez, conta com o tambor na relação que é o fazer, o assentar. Fazer, escrevem Oro e Anjos (2008), é o verbo mais importante desse regime afro-brasileiro de existência. Retirar o tambor do quarto de santo ou de suas imediações parece ser um ato de desmembramento de um acontecimento que é o próprio ato de assentar e do complexo de dependências aí combinadas. No caso de Luis, bem como de diversos outros alabês, mover o tambor de obrigação (ou seja, "tirá-lo de casa") quer dizer colocar certos tipos de dependências em descontinuidade, pois o instrumento foi posto em participação ao orixá que, lembremos, foi particularizado. $\mathrm{O}$ axé de tambor, por outro lado, é a parte móvel e acompanha o alabê em seus toques "na rua". Para Luis, seu tambor de obrigação o ajuda na "condução da energia rítmica", na memorização das rezas ou quando, durante a condução de um Batuque, as rezas "vem", todas estas sendo propriedades importantes para sua prática como alabê. Ao sair de casa para tocar o tambor de trabalho, o tambor de obrigação o auxilia e, enquanto força, o acompanha.

Etto Mendes, conhecido alabê do bairro Restinga, em Porto alegre, considera que os vínculos estabelecidos entre o tambor de obrigação e as divindades também se estendem aos seus outros tambores (tambores de trabalho), adicionando novos contornos à atuação desses instrumentos.

Tenho quatro [tambores]. Um eu não toco, que é do meu aprontamento [tambor de obrigação], né? Não que eu não possa tocar, mas a energia que eu trago da rua, dos outros tambores que eu toco, ela é coligada com aquele tambor. Então a energia vai pra lá (para o tambor/quarto de santo), a energia negativa vai pra lá. E lá os santos, os orixás, eles têm o trabalho de tirar aquilo. Eles me aliviam, vai pra lá, eles tiram de lá. ${ }^{18}$

\footnotetext{
${ }_{16}$ É também o tambor de obrigação que contribui para que sejam firmados os vínculos entre o alabê e o terreiro/família ao qual é filiado. Essa relação é comumente ritualizada no Batuque, poucos dias após o serão, quando, durante as cantigas de Xangô, o alabê recebe seu novo tambor e canta os axés (cantigas) das obrigações dos/das pais/mães de santo que compõem a estrutura hierárquica da casa.

17 Onde o orixá responde pode ser aqui compreendido como o lugar por excelência que, ao mesmo tempo, é e faz habitar o orixá particularizado.

18 Entrevista realizada em julho de 2016.
} 
O caso apresentado por Etto nos mostra que a utilização de instrumentos distintos, motivada pela necessidade de circulação, não resulta no rompimento de certos vínculos, mas na alteração nos graus de participação, pois, como vimos, além de se configurar como assentamento, como representante dos demais tambores, como mediador no recebimento do axé de tambor, e, ainda, como passe para o universo dos tocadores de tambor, o tambor de obrigação é também responsável pela proteção e purificação do alabê e dos tambores de trabalho. Impedido de circular, pois não deve "sair de casa", o tambor de obrigação limpa as energias dos tambores que circulam. Tambores dependem uns dos outros para atuar.

Como exemplo de outras formas de vínculo ou extensão envolvendo os dois tambores, Alexandre de Bará e outros alabês afirmam ter recebido o axé de tambor também em suas mãos, o que garante ao alabê os axés necessários ao toque dos tambores de trabalho, ou seja, ao toque "pra fora". Alexandre faz referência ao processo citado anteriormente, em que o axorô ( sangue) do animal sacrificado deve escorrer sobre o corpo do tambor de obrigação e sobre as mãos do alabê. Também aqui o louva-a-deus se move, deixa-se enxergar.

[O axé de tambor] tá no tamborizinho lá, mas é lá dentro [do quarto de santo]. Mas, pra fora... "Ah tu tem que tocar num tambor que tem obrigação". Não, não tem. Até porque se eu tocar no meu tambor que tem obrigação, como é que eu vou chegar numa festa e "vai lá, Leonardo". ${ }^{19}[\mathrm{Tu}]$ não tem axé de tambor, aí vai tocar lá no meu tambor? ${ }^{20}$

Luis de Xapanã complementa, também considerando o toque "pra fora":

Tem gente que diz que deveria ter um tambor pra cada situação [um para cada modalidade ritual]. Eu até concordo. Mas o tambor que foi feito o ritual tá resguardado, tu não vai tirar ele pra fora, e o axé, de fato, tu carrega nas tuas mãos. Se, por ventura, eu vejo um cara que tocou tambor na casa do João, tocou Quimbanda naquele tambor e, na minha casa, daqui uma semana, ele tocou pra santo [Batuque], vou ser bem sincero, eu não vou ver problema nisso. A energia tá na mão dele. ${ }^{21}$

Uma vez que o axé de tambor não está presente apenas no tambor de obrigação, mas também nas mãos do alabê, o corpo emerge como meio de extensão desse axé, conferindo ao alabê a possibilidade do movimento e de manipulação de outros instrumentos, até mesmo os crus (não consagrados). Assim, no caso do tambor de obrigação, sua presença restrita ao quarto de santo é apenas aparente, pois parte dele acompanha o alabê em sua atividade nômade. É preciso acompanhar movimentos, seguir alguns instrumentos e alabês para que os tambores de obrigação sejam vistos.

Há, ainda, uma última consideração a ser feita antes de avançarmos para a apresentação do próximo tipo de tambor, o tambor da casa. A utilização do tambor de trabalho com o objetivo de alcançar espaços não ocupados pelos tambores de obrigação não ocorre com a simples compra de um novo instrumento. Ocorre, por outro lado, a partir de certos ajustamentos (ou "modulações") que vão desde a consagração específica para a modalidade ritual a qual será destinado até a proposital "não consagração" do instrumento (tambor cru).

\footnotetext{
19 Durante os rituais, é comum que o alabê contratado convide outros alabês, sejam eles amigos ou visitantes, para tocar.

20 Entrevista realizada em abril de 2018.

${ }^{21}$ Entrevista realizada em junho de 2018.
} 
Fala-se comumente, por exemplo, que um tambor de trabalho consagrado aos exus ( também chamado de "tambor cruzado"), uma opção possível, não deve ser utilizado em rituais de Batuque ou Umbanda. Há aqui incompatibilidades energéticas que atravessam toda a prática religiosa. O alabê Vagner D’Agandjú nos dá um exemplo:

$O$ [meu] tambor pra Umbanda é um tambor que vai servir pra tocar tanto pra exu (Quimbanda) quanto pra preto velho (Umbanda). O [meu] tambor do exu não é um tambor vice e versa. O ideal é que se toque o tambor da Umbanda pra exu, se quiser, e que não se toque o tambor do exu, consagrado, pra Umbanda. Um tambor consagrado pra exu pra chamar caboclo fica estranho. ${ }^{22}$

Alexandre de Bará, na continuação da entrevista citada anteriormente, novamente contribui expondo dinâmicas energéticas semelhantes. O alabê afirma ter apenas dois tambores, o tambor de obrigação que, tal como no caso dos outros alabês, "não sai do quarto de santo", e outro que é propositalmente não consagrado, "cru", para que possa ser utilizado em rituais de Batuque, Umbanda e Quimbanda.

\section{Tu já fez alguma coisa nele [no tambor de trabalho]?}

De axé? Não fiz porque, como eu tenho só ele e eu toco Quimbanda, toco nação, então eu teria que preparar pra um deles, então eu não poderia tocar no outro. Então tambor pra mim hoje tem que ser cru, porque eu não sei o que eu vou tocar, o que eu vou fazer. O tambor que tu faz obrigação não é o que tu toca. O tambor que tu faz obrigação fica no quarto de santo.

Outro alabê, Toco Bará, comentou sobre seu tambor enquanto nos preparávamos para ir a um Batuque em Alvorada (Porto Alegre). Olhei para o instrumento de cor vermelha, com uma tonalidade que tendia para a cor rosa, e perguntei:

\section{Esse tá cruzado?}

Não, porque eu posso tocar com ele Umbanda e Quimbanda, e nação também, sendo ele cru. Depois que tu cruzar ele com santo, o mesmo axorô (sangue) que come nele vai comer no teu santo. Então tu vai ter que usar ele só pra santo, e vai ter que reservar ele. Eu tenho outro, [...] já montado pra tocar pra exu. Esse de exu, já écruzado pra exu. Só uso pra exu e mais nada. ${ }^{23}$

Há ainda o caso de os alabês que preferem ter tambores distintos para cada modalidade ritual, seja o instrumento consagrado ou cru. Em entrevista realizada em setembro de 2016, o alabê Frank Morais, morador da cidade de Alvorada, destaca:

Aquele tambor [de obrigação] eu fiz uma obrigação com ele, obrigação de santo. Daí eu não podia pegar aquele tambor e sair a tocar pra fora. Eu até ia com ele. Aquele tambor eu vou deixar só pra casa. Aí eu resolvi fazer um com o Jorge [artesão]. Existem nação, Umbanda e de exu. A pessoa separa as coisas. Então eu tenho tambor de nação, de Umbanda e de exu, os três lados. Eu procurava não misturar.

Frank exemplifica a afirmação feita anteriormente, de que um único tambor pode exercer simultaneamente o papel de tambor de obrigação e de trabalho, mas que, em certo momento da trajetória religiosa e profissional do alabê, os papéis se separam em tambores distintos. O tambor se avatariza. Por esse motivo, Frank expõe o desejo de

\footnotetext{
22 Entrevista realizada em dezembro de 2016. Em suma, Vagner afirma que os tambores consagrados na Umbanda podem ser utilizados em rituais de exu. Por outro lado, os tambores consagrados aos exus (Quimbanda) não devem ser utilizados em rituais de Umbanda.

${ }_{23}$ Entrevista realizada em abril de 2018.
} 
manter seu tambor de obrigação em casa, resultando na encomenda de novos tambores (tambor de trabalho) para que possa circular entre os terreiros. Frank também fala sobre a necessidade de "separar as coisas", o que leva o alabê a possuir um tambor para cada modalidade ritual, obedecendo características estéticas e sonoras específicas.

Os casos apresentados indicam que ajustamentos são necessários, tendo em vista a compatibilidade de energias. Além disso, a consagração liga o instrumento a certos compartimentos energéticos, limitando movimentos e relações - ou mesmo impondo novos tipos de relações. Os alabês evidenciaram que tambores consagrados aos exus, por exemplo, não devem ser utilizados em rituais de Umbanda ou Batuque; ou, ainda, que tambores consagrados para o Batuque não devem ser utilizados em rituais de exu. Nesse caso, alguns alabês preferem manter o instrumento cru, evitando que a consagração limite a circulação, esta que, como vimos, é necessária para a atividade profissional. Em todos os casos, há um trabalho atento às compatibilidades energéticas e às diferentes maneiras de regular forças para que certos movimentos sejam possíveis e para que esses objetos possibilitem passagens e atravessamentos entre domínios espirituais.

\section{Tambor da casa}

Há, por enquanto ${ }^{24}$, um terceiro avatar dos ilús a ser considerado: o tambor da casa. Este, por sua vez, e ao contrário dos dois tambores anteriores, não possui necessariamente relações diretas com os alabês, mas está vinculado aos terreiros, seus respectivos líderes religiosos e às divindades que os compõem. Fala-se, portanto, do tambor de Oxalá, referindose ao tambor consagrado a Oxalá em um terreiro de um pai de santo filho de Oxalá. E assim como no caso dos alabês, muitos pais de santo consagram o tambor da casa ao orixá Xangô, o dono do instrumento, mesmo que seu orixá de cabeça seja Xapanã, Odé, ou outro orixá do orumalé.

Tal como me afirmou um dos alabês da "velha guarda" do Batuque gaúcho, Chamim de Agandjú, "[...] cada casa tem que ter um tambor próprio, porque é a marca de tudo. Tambor pronto (consagrado) quer dizer 'casa aberta'"25. Lembremos que "a casa" deve ser compreendida como um espaço de confluências de energias, de divindades, pessoas e objetos, como um lugar de iniciações e feituras de pessoas. Cada cômodo, cada compartimento abriga diferentes historicidades, presenças e modulações do axé expressos em uma espacialidade mítica.

Barbosa Neto (2012) nos lembra que a relação entre um chefe e a sua casa é como a relação entre uma divindade seu assentamento. A casa é ele, mas é também o lugar no qual habita. Esse autor destaca que o axé do chefe, aquilo que constitui propriamente a sua pessoa, não se separa, de um lado, da casa na qual ele foi feito e dos deuses que comeram nele, e, de outro, dos filhos que ele faz ao fazer as relações com suas respectivas divindades. Se é possível afirmar que o pai santo, “[...] por intermédio do axé contido

\footnotetext{
${ }^{24}$ Uso "por enquanto" porque outras versões de tambores poderão ser discutidas em futuras oportunidades. Algumas delas foram apresentadas em Almeida (2019).

${ }^{25}$ Entrevista realizada em abril de 2018.
} 
em seu corpo, é a casa, é precisamente porque a sua pessoa é composta por várias outras: aquelas que ele faz e aquelas com as quais ele faz fazer" (BARBOSA NETO, 2012, p. 111).

Nessa perspectiva, o tambor da casa se constitui como um dos elementos indispensáveis para a composição da pessoa/casa do pai ou mãe de santo e sua experiência espiritual, juntamente com os seus assentamentos, os assentamentos de seus filhos e os diferentes espaços que fazem confluir a vida religiosa e a vida doméstica. Como me disse certa vez o pai de santo e alabê João Carlos de Xangô, o tambor consagrado no terreiro é tão indispensável quanto os demais axés necessários a um pai de santo, como o axé de faca (obé), importante para a realização da sacralização dos animais, e o axé de búzio (ifá).

Alguns pais e mães de santo me falaram sobre a necessidade de sempre manter seus tambores em atividade, assim como também deveria acontecer com os outros objetos, com os cômodos da casa e com o axé, e, por isso, pediam que os alabês contratados tocassem o instrumento da casa. Pai Deco de Oxum, pai de santo da Zona Sul de Porto Alegre, costuma exigir que os alabês contratados utilizem o tambor da Oxum, em especial no momento em que, durante o Batuque, o olokori da Oxum é tocado (trata-se da reza da sua Oxum). Assim também costumam ser feito em outros terreiros que visitei, como o de Mãe Iara de Xangô, residente em Viamão, que pede aos alabês que toquem o tambor de Xangô; e pai Manuel de Oxalá, com relação ao tambor da sua casa.

Pai Gelson de Bará, cujo terreiro está situado no bairro Jardim Leopoldina, em Porto Alegre, possui dois amplos salões em sua casa. No andar superior fica o salão destinado ao toque para os orixás e para as entidades da Umbanda. No andar inferior está situado o salão destinado aos toques de Quimbanda (exus e pombagiras). Para cada andar há equipes distintas de tambores que em hipótese alguma devem subir ou descer. Pai Gelson possui dois tambores consagrados, um ao orixá Xangô e outro ao orixá Bará (seu orixá de cabeça), guardados no salão superior. Esses são os únicos tambores que nunca devem "sair pra rua". Como no caso dos pais de santo citados anteriormente, pai Gelson faz questão de que seus instrumentos sejam tocados durante os rituais, pois, segundo me foi dito em uma de nossas conversas, "o tambor da casa tem que falar", em especial nos serões, quando acontecem os rituais de sacralização dos animais. O tambor deve falar, pois, uma vez que se tornou participante e testemunha, tem algo muito importante a dizer sobre o axé que a casa é e faz habitar.

No andar inferior, três tambores crus são utilizados para os toques de exu e podem "sair pra rua" sempre que for necessário. O pai de santo justifica que seus tambores são crus porque "o exu tudo é caminho, tudo é rua, tudo entra". O cruzamento, tal como venho afirmando, limita a ressonância dos instrumentos a certas intensidades energéticas. Não cruzar o tambor, nesse caso, remete ao desejo de não bloquear fluxos. Pai Gelson parece querer que o tambor se faça objeto dos atravessamentos e das intensidades características do universo dos exus, como se o próprio instrumento fosse uma encruzilhada. Mediado pelo tambor, diferentes tipos de energia compõem a casa/pai de santo.

Apesar da importância do tambor da casa para a manutenção do axé, alguns taboreiros também relatam o desaparecimento desse instrumento nos terreiros gaúchos ou, em alguns casos, sua subutilização. Chaninho de Bará, tamboreiro há mais de 45 anos, afirmou em entrevista: "Hoje tem casas que não tem tambor, tu tem que levar. A maioria das casas tinha seu próprio tambor, era raro casa que não tinha. Mas hoje eu entendo 
alguns dos tamboreiros, dos alabês, no caso, que eles levam os tambores deles porque eles tão mais acostumados com o tambor deles" ${ }^{\prime 26}$. Antônio Carlos de Xangô, que também pertencente às gerações mais antigas do Batuque, me contou sobre os tambores da casa: "Antigamente toda casa tinha que ter seu ilú em casa. Então, o alabê que chegava, era contratado, ele tocava no ilú da casa" ${ }^{\prime 2}$. André de Agandjú, alabê e pai de santo, faz comentário semelhante: "Escuta bem o que eu vou te falar agora. Isso, de tamboreiro ter seu próprio tambor, é de anos pra cá. Antigamente não, era da casa. O tamboreiro chegava e tocava com o tambor da casa" ${ }^{28}$. Diz, ainda, o tamboreiro Alfredo Ferreira, conhecido em Porto Alegre (contra a sua vontade) como Ecó: “Antigamente era muito raro tamboreiro carregar o instrumento, porque tinha na casa. Isso aí era muito raro. Hoje que cada um faz o seu tambor e leva, mas antigamente não era assim”29.

É difícil precisar a partir de uma única linha explicativa quais as razóes para a intensificação do uso do tambor pessoal por parte dos alabês. Mas, como indicam Antonio Carlos e Chaninho, haveria relação com a facilidade de se produzir tambores nos dias atuais, somada ao fato de os alabês preferirem usar seus próprios instrumentos. Apostaria ainda no processo de autonomização e profissionalização a que passaram os alabês, pois ser um bom profissional exige a posse de um "instrumento de trabalho". Além disso, muitas casas não possuem um quadro fixo de alabês, tal como foi analisado por Braga (2013), o que em muitos casos impossibilita que o tambor da casa receba os cuidados e as manutenções constantes necessários a uma boa performance.

\section{Outros Mimetismos}

Por fim, destaco um trecho de uma entrevista realizada pelo programa Kizomba (em maio de 2018), durante uma transmissão ao vivo apresentada por Israel Ávila na rede social Facebook. No programa em questão, produzido pela empresa de mídia portoalegrense Kizomba, o tema da noite foi "Tambor". Seis alabês foram convidados para responder às perguntas enviadas pelas pessoas que acompanhavam o programa on-line. Uma das perguntas resultou em um debate que envolveu dois alabês, Rafael e Sandrinho, e o apresentador do programa, Israel Ávila.

Israel Ávila: Rafael, eu sei que tu nem toca exu. O mesmo tambor que toca exu pode tocar pro orixá?

Rafael: Com certeza não, obviamente que não.

Nesse momento, os outros alabês entreolharam-se e expressaram ter opiniões diferentes daquela exposta por Rafael. É importante ressaltar que Rafael é, entre os alabês presentes, um dos que se dedica apenas aos toques de nação (Batuque). Após perceber as divergências no debate, Israel Ávila interveio:

\footnotetext{
26 Entrevista realizada em dezembro de 2016.

27 Entrevista realizada em março de 2016.

28 Entrevista realizada em abril de 2016. Na continuação, André complementa: “toda casa de santo tem que ter um tambor, independentemente se ele é bom ou é ruim, ou se vai ser usado ou não. Tem que ter um tambor".

29 Entrevista realizada em julho de 2018.
} 
Israel Ávila: Já dividiu opinião!

Rafael: Eu acho assim, muitas vezes o tambor de orixá é matado, vai o axorô do quatro pé. O tambor vai comer junto, o ilú vai ficar lá de obrigação. Então eu acho que, na minha opinião, não é correto o alabê, o tamboreiro, tocar uma festa de exu e no final de semana vai tocar um Batuque.

Israel Ávila: Vou pedir pra passar [a palavra] pro Sandrinho, por que ele achou que não era o que tu falou.

Sandrinho: Eu acho assim, o tambor, quando a gente deita (obrigação), tá fazendo o axé de alabê (axé de tambor) ... O tambor que a gente deita pra fazer o chão pra Xangô, aquele tambor é sagrado. Aquele tambor não pode ser usado pra exu.

Israel Ávila: Então tu concorda com o que ele tá falando?

Sandrinho: Concordo, mas só que ninguém faz isso. Eu tenho aquele tambor [de obrigação] até hoje, desde criança, que eu fiz com oito anos de idade. Eu não uso ele. Eu já usei ele nos Batuque na casa da minha mãe de santo que já faleceu, foi onde que eu toquei os Batuque com ele, só lá dentro, naquela casa, só dentro desse ilê. Então esse tambor que a gente monta (cru) é pra tocar em todos os lugares. Esse tambor não é cruzado. Esse tambor sagrado que a gente usa (tambor de trabalho), não é o mesmo que tu tem a tua obrigação lá, entendeu? Então a gente pode usar qualquer tambor, a gente leva pra usar. Pode sim, mas não aquele tambor que tu deitou pro Xangô (tambor de obrigação).

Retomemos novamente os movimentos do louva-a-deus e seus processos miméticos. Se, no primeiro momento deste artigo, o mimetismo se mostrou como um desafio ao pesquisador, como um objeto que se apresenta mimetizado no fundo performático de outro, no caso em questão, o mimetismo se expressa pelos desacordos relacionados à identificação das diferentes versões do instrumento por parte dos próprios alabês, o que contribui para destacar a multiplicidade de possibilidades que envolvem a presença dos tambores nessas religiões. Essa multiplicidade, ressaltemos, se deve, entre outros fatores, às potencialidades de diversificação e de concretização próprias do axé e das energias que atuam no mundo. Sandrinho deixa claro que, em sua prática diversificada - que engloba a Umbanda, a Quimbanda e a Nação -, os tambores em questão parecem ser os mesmos, mas não são. O alabê nos alerta para o fato de que "esse tambor sagrado que a gente usa", fazendo referência ao tambor de trabalho e ao mesmo tempo não deixando de ressaltar sua sacralidade, "não é o mesmo que tu tem a tua obrigação lá [no quarto de santo], entendeu?". A divergência entre os dois alabês parece ter origem em suas distintas práticas profissionais e, consequentemente, nos distintos modos de relação com variados tipos de força: um que se dedica apenas ao Batuque e outro que transita entre as três modalidades. Não incluindo a Quimbanda em sua agenda de toques, Rafael vê com estranhamento o uso dos tambores de Batuque nos rituais de Quimbanda. Para Sandrinho, o estranhamento é compreensível, uma vez que concorda que o tambor de obrigação não deve ser utilizado em rituais de exu. O erro do outro alabê, na perspectiva de Sandrinho, teria sido não incluir em seu argumento os tambores cru/de trabalho, ou seja, os instrumentos que possibilitam outros tipos de movimento e que, ao mesmo tempo, evitam que o tambor de obrigação transite por espaços impróprios e propiciam a extensão do axé de tambor que por meio do tambor de obrigação foi adquirido. 


\section{Considerações Finais}

A existência dos três avatares apresentados nos leva a questionar por quais tipos de mudança passaram os tambores ao longo dos processos de transformação do campo religioso afro-gaúcho, em especial a partir dos arranjos entre a Umbanda, a Quimbanda e o Batuque, bem como na ampliação da atividade profissional dos alabês. Considerando que o Batuque já está presente no Rio Grande do Sul desde o século XIX, com o surgimento da Umbanda, a partir da década de 1930, e da Quimbanda como modalidade ritual independente, a partir da década de 1970, as incompatibilidades energéticas entre essas modalidades podem ter exigido a utilização de diferentes avatares do instrumento. Nesse sentido, tambores distintos também são meios de passagens entre diferentes modalidades rituais e energias diversas, como extensões que mediam e possibilitam movimentos. Não se trata apenas de instrumentos diferentes, selecionados isoladamente para atuar em funções distintas, como um cozinheiro que seleciona facas distintas para o corte de diferentes tipos de alimento. O que busquei ressaltar aqui é a maneira como esses objetos atuam nos ajustamentos de forças, possibilitando que apontemos conexões e dependências entre eles, bem como sua relação com as transformações no campo afrorreligioso.

Além disso, considerando que a maioria dos terreiros do Rio Grande do Sul pratica as três modalidades (ORO, 2002; CORRÊA, 2006), poderíamos questionar o que os três tambores apresentados podem nos dizer sobre o processo de autonomização dos alabês gaúchos e as transformações nos processos de iniciação. Seria o tambor de trabalho uma cisão provocada pela autonomização dos alabês que circulam por diversos espaços e pelas incompatibilidades entre energias surgidas após a consolidação da Umbanda e da Quimbanda no território gaúcho? Ao longo do processo de pesquisa visitei terreiros em que o tambor de obrigação era também o tambor da casa. Essa situação só era possível porque o terreiro em questão possuía um alabê fixo, um filho de santo. Nos terreiros que não possuíam um quadro fixo de alabês, era necessário realizar a contratação de profissionais, o que impossibilitava que o tambor da casa atuasse também como tambor de obrigação. Além disso, afirmam alguns pais e mães de santo, o trânsito dos alabês entre terreiros, "passando de mão em mão" ao longo de sua trajetória religiosa, leva diversas lideranças religiosas a preferir manter a separação entre os dois instrumentos, uma vez que nada garante que o alabê permanecerá por muito tempo em uma mesma casa.

Argumentei neste artigo que os tambores apontam para os diferentes "graus de participação" entre pessoas e objetos às divindades e forças, fruto de certas modulações do axé. Casos como os dos alabês Etto Mendes e Alexandre de Bará, citados anteriormente, evidenciam que as incompatibilidades entre forças se tornam contornáveis a partir da manipulação dos graus de participação. No caso de objetos impedidos de circular ou de atuar em certos espaços, situações ou domínios energéticos, a participação não é interrompida por completo, mas é mantida a partir de vínculos menos ou mais diretos, fazendo com que os próprios objetos atuem mediando novas participações. E é durante esse percurso de mediação que observamos o surgimento de processos miméticos. A relação entre pessoas, orixás, assentamentos, tambores e forças nos mostram que pesquisar as religiões afro-brasileiras é, portanto, abrir-se para a possibilidade de analisar dependências e identificar possíveis mimetismos. 


\section{Referências}

ALMEIDA, Leonardo Oliveira de. Fonografia religiosa afro-gaúcha: o ritual e o gravado no contexto de novas artisticidades. Debates do NER, [s.l.], v. 1, n. 33, p. 197-234, 2018.

ALMEIDA, Leonardo Oliveira de. Tambores de todas as cores: práticas de mediação religiosa afro-gaúchas. 2019. 235p. Tese (Doutorado) - Programa de Pós-Graduação em Antropologia Social, Universidade Federal do Rio Grande do Sul, 2019.

AMARAL, Rita. Coisas de Orixás: notas sobre o processo transformativo da cultura material dos cultos afro-brasileiros. Revista Inter e Transdisciplinar de Ciências Sociais, Porto, Portugal, v. 41, n. 3-4, p. 103-110, 2001.

AUGRAS, Monique. O duplo e a metamorfose: a identidade mítica em comunidades nagô. Petrópolis: Vozes, 2008.

BARBOSA NETO, Edgar Rodrigues. A máquina do mundo: variações sobre o politeísmo em coletivos afro-brasileiros. 2012. 393p. Tese (Doutorado em Antropologia Social) - Universidade Federal do Rio de Janeiro, Rio de Janeiro, 2012.

BARBOSA NETO, Edgar Rodrigues. A geometria do axé: o sincretismo como topologia. Revista de@ntropologia da UFSCar, [s.l.], v. 9, n. 2, jul.-dez. 2017.

BASTIDE, Roger. Imagens do Nordeste místico em branco e preto. Rio de Janeiro: Cruzeiro, 1945.

BASTIDE, Roger. Estudos afro-brasileiros. São Paulo: Perspectiva, 1983.

BASTIDE, Roger. O candomblé da Bahia (rito Nagô). São Paulo: Companhia Editora Nacional, 1961.

BÉHAGUE, Gerard. Patterns of candomblé music performance: an Afro-Brazilian religious setting. Performance Practice: Ethnomusicological Perspectives, [s.l.], v. 12, 1984.

BRAGA, Reginaldo Gil. Batuque Jêje-Ijexá em Porto Alegre: a música do culto aos orixás. Porto Alegre: Fumproart, 1998.

BRAGA, Reginaldo Gil. Tamboreiros de Nação: música e modernidade religiosa no extremo sul do Brasil. Porto Alegre: UFRGS Editora, 2013.

CORRÊA, Norton. Os Vivos, os Mortos e os Deuses. 1988. 474p. Dissertação (Mestrado em Antropologia Social) - Universidade Federal do Rio Grade do Sul, Porto Alegre, 1998.

CORRÊA, Norton. O batuque no Rio Grande do Sul: Antropologia de uma religião afro-RioGrandense. São Luiz: Cultura \& Arte, 2006.

CORRÊA, Norton. Os bimembranófonos iorubá no Brasil. ERAS: European Review of Artistic Studies, [s.l.], v. 2, n. 3, p. 42-76, 2011.

CORRÊA, Norton. Tambores Iorubás no Brasil. Revista Africa, [s.l.], v. 1, jul.-dez., 2014.

GIDAL, Marc Meistrich. Spirit Song: Afro-Brazilian Religious Music and Boundaries. New York: Oxford University Press, 2016.

GIUMBELLI, Emerson Alessandro; ALMEIDA, Leonardo Oliveira de. O enigma da Quimbanda: formas de existência e de exposição de uma modalidade religiosa afro-brasileira no Rio Grande do Sul. Revista de Antropologia, [s.l.], v. 64, n. 2, 2021.

GOLDMAN, Marcio. Formas do saber e modos do ser: observações sobre multiplicidade e ontologia no candomblé. Religião e Sociedade, [s.l.], v. 25, n. 2, p. 102-120, 2005.

GOLDMAN, Marcio. Histórias, devires e fetiches das religiões afro-brasileiras: ensaio de simetrização antropológica. Análise Social, [s.l.], n. 190, p. 105-137, 2009.

GOLDMAN, Marcio. O dom e a iniciação revisitados: o dado e o feito em religiões de matriz africana no Brasil. Mana, Rio de Janeiro, v. 18, n. 2, p. 269-288, 2012. 
HERSKOVITS, Melville J. Drums and drummers in Afro-Brazilian cult life. The Musical Quarterly, [s.l.], v. 30, n. 4, p. 477-492, 1944.

HOEHNE, Markus V. Mimesis and mimicry in dynamics of state and identity formation in northern Somalia. Africa, [s.l.], v. 79, n. 2, p. 252-281, 2009.

KREBS, Carlos Galvão. Estudos de Batuque. Porto Alegre: Instituto Gaúcho de Tradição e Folclore, 1988.

LATOUR, Bruno. Reagregando o social: uma introdução à teoria do ator-rede. Salvador: Edufba, 2012.

LEISTNER, Rodrigo Marques. Os outsiders do além: um estudo sobre a quimbanda e outras 'feitiçarias' afro-gaúchas. 2014. 388p. Tese (Doutorado em Ciências Sociais) -Universidade do Vale do Rio dos Sinos, São Leopoldo, 2014.

ORO, Ari Pedro. Religiões afro-brasileiras do Rio Grande do Sul: passado e presente. Estudos Afro-Asiáticos, [s.l.], v. 24, n. 2, p. 345-384, 2002.

PARÉS, Luis Nicolau. Xangô nas religiões afro-brasileiras: “aristocracia" e interações "sincréticas". Revista Africa(s), [s.l.], v. 1, n. 1, p. 149, 2014.

PLATE, Brent et al. On the Agency of Religious Objects: A Conversation. Web blog post. Material Religions. [2015]. Disponível em: http://materialreligions.blogspot.com.br/2015/10/ on-agency-of-religious-objects.html. Acesso em: 3 dez. 2015.

RABELO, Miriam. O presente de oxum e a construção da multiplicidade no candomblé. Religião e Sociedade, [s.l.], v. 35, n. 1, 2015.

SANSI, Roger. "Fazer o santo": dom, iniciação e historicidade nas religiões afro-brasileiras. Análise Social, [s.l.], n. 190, p. 139-160, 2009.

SANSI, Roger. Shrines, substances, and miracles in Afro-Brazilian Candomblé. Anthropology G Medicine, [s.l.], v. 18, n. 2, p. 271-283, 2011.

SANTOS, Juana Elbein dos. Os nagô e a morte. Petrópolis: Vozes, 2012.

SILVEIRA, Ana Paula Lima. Batuque de mulheres: aprontando tamboreiras de nação nas terreiras de Pelotas e Rio Grande, RS. 2008. 163p. Dissertação (Mestrado em Antropologia Social) - Universidade Federal do Rio Grande do Sul, Porto Alegre, 2008.

TADVALD, Marcelo. O batuque gaúcho: notas sobre a história das religiões afro-brasileiras no extremo sul do Brasil. In: DILLMANN, Mauro (org.). Religióes e religiosidades no Rio Grande do Sul. Porto Alegre: Autores; ANPUH, 2016. v. 4. p. 141-168.

WOLFF, Luiza Spinelli Pinto. Seres materiais entre sons e afetos: uma etnografia arqueológica dos objetos em terreiras de Pelotas/RS. 2016. 143p. Dissertação (Mestrado em Antropologia) - Universidade Federal de Pelotas, Pelotas, 2016.

\section{Leonardo Oliveira de Almeida}

Doutor em Antropologia Social pela Universidade Federal do Rio Grande do Sul. Pesquisador DCR CNPq/FUNCAP no Programa de Pós-Graduação em Antropologia da Universidade Federal do Ceará. Endereço profissional: Universidade Federal do Ceará, Av. da Universidade, n. 2.995, Benfica, Fortaleza, CE. CEP: 60020-181.

E-mail: leonardoalmeida_cs@yahoo.com.br

ORCID: https://orcid.org/0000-0002-0958-4888

\section{Como referenciar este artigo:}

ALMEIDA, Leonardo Oliveira de. Mimetismos Afro-Brasileiros: dependências e algumas formas de ser. Ilha - Revista de Antropologia, Florianópolis, v. 23, n. 3, p. 155-175, setembro de 2021 . 